\title{
Identification of emergent systems of play in green urban spaces in geocaching and geoplay by geographic information (GI) technologies
}

\author{
Tore Gulden ${ }^{\dagger}$ \\ Department of Product Design \\ OsloMet - Oslo Metropolitan \\ University \\ Oslo, Norway \\ tgulden@oslomet.no
}

\author{
Arild Berg \\ Faculty of Technology, Art and \\ Design \\ OsloMet - Oslo Metropolitan \\ University \\ Oslo, Norway \\ arildber@oslomet.no
}

\author{
Frode Eika Sandnes \\ Department of Information \\ Technology \\ OsloMet - Oslo Metropolitan \\ University \\ Oslo, Norway \\ frodes@oslomet.no
}

\begin{abstract}
In this demo project we explore quantifiable data engendered by emergent geoplay games as a source, to research the use of urban green space impacts on in health and well-being. By the establishing of an emergent geogame built on a GPS dependent interface for smartphones, one facilitates diverse and unanticipated behavior that produce digital data by movements, actions according to the rules, and documentation. The research will involve the exploration of the empirical data produced by play in green urban spaces in accordance to the core concepts of spatial information, fun and well-being.
\end{abstract}

\section{KEYWORDS}

Gameplay, geocatching, spatial information,

\section{Introduction}

With this project, we aim to explore how geocaching games or "geographic gameplay" (Ahlqvist \& Schlieder, 2018, p. 2) influence the use of green urban spaces, enhance mobility, and foremost function as a platform for the emergence of new play systems and consequently behavior as factors of health and experienced well-being and fun.

\section{Approach and Demo}

Geographic gameplay involves utilizing spaces such as cities, forests, parks among others, into a real world board games that rely on geographic information technologies and mixed reality platforms. That is, both digital and physical realities are present in these games. Pokémon GO is an example of such a game. The rules in Geoplay games differ; typically, they comprise activities by spotting or caching of messages, surprises, hints, challenges, and so forth, hidden at a defined area. In this grand playing field the player use of maps and compasses or geographic information technologies.

Geoplay gameplay function on a progressive or emergent game structure, or a combination of these. Progressive game structures lead the player through a pre-designed line of play as opposed to emergent game structures (Juul, 2003). Emergent games thus, stimulate types of play that are unplanned or unknown. One example of such a game is parkour, which is oriented about the manner of execution and mastery, rather than the purpose in accordance to rules (Kreft, 2015; Perinbanayagam, 2006).

Kuhn has researched on how what spatial information is and how it can be used, and in extension how it can contribute to transdisciplinary research (2012). He proposed a set of 10 core concepts of spatial information, intended to be meaningful to scientists who are not specialists of spatial information: location, neighborhoods, field, object, network, event, granularity, accuracy, meaning, and value (Kuhn, 2012, p. 2267).

For the demo we propose to show a mockup of the main function of the game with the intent to utilize the environment as a game board by use of game mechanics, that is, the people tested must make use of the area, people, and coincident entities within the specific context during play.

The research involves the exploration of quantifiable data engendered by emergent geoplay games as a source, to research the use of urban green space impacts on in light of health and well-being. By the establishing of an emergent geogame built on a GPS dependent interface for smartphones, one facilitates diverse and unanticipated behaviour that produce digital data, IoT, and AI, by movements, actions according to the rules, and documentation. The research will involve the exploration of the empirical data produced by play in green urban spaces in accordance to the core concepts of spatial information by Kuhn and well-being and fun. 


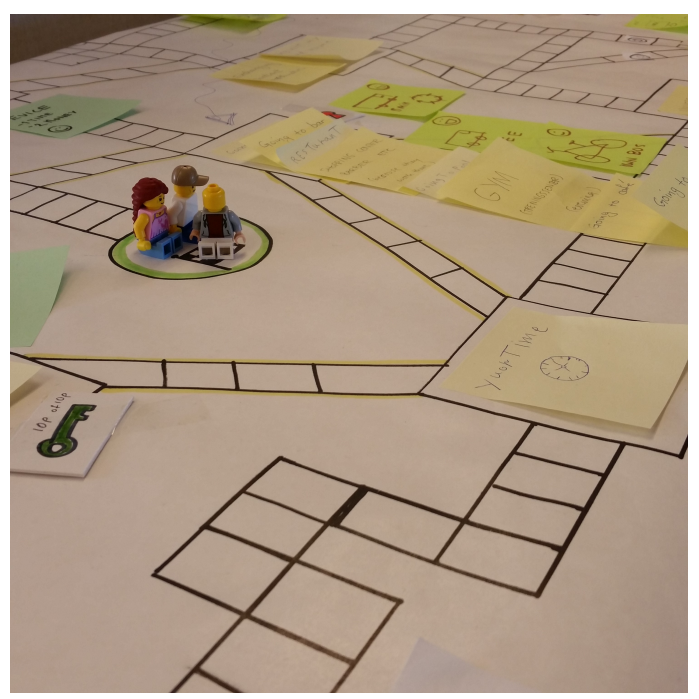

Figure: Game made for the purpose of enabling a natural dialogue among asylum seekers as an alternative to interviews

\section{REFERENCES}

Aad, G., Abajyan, T., Abbott, B., Abdallah, J., Abdel Khalek, S., Abdelalim, A. A., . . . Collaboration, A. (2012). Search for magnetic monopoles in sqrt[s] $=7 \mathrm{TeV}$ pp collisions with the ATLAS detector. Phys Rev Lett, 109(26), 261803.

Ahlqvist, O., \& Schlieder, C. (2018). Introducing Geogames and Geoplay: Characterizing an Emerging Research Field. In O.

Ahlqvist \& C. Schlieder (Eds.), Geogames and Geoplay: Gamebased Approaches to the Analysis of Geo-Information (pp. 1-18). Cham: Springer International Publishing.

Juul, J. (2003). The Game, the Player, the World: Looking for a Heart of Gameness. Paper presented at the Level Up: Digital Games Research Conference Proceedings, Utrecht.

Kreft, L. (2015). Aesthetic Imagination in Football. Sport, Ethics and Philosophy, 9(2), 124-139.

doi:10.1080/17511321.2015.1048821

Kuhn, W. (2012). Core concepts of spatial information for transdisciplinary research. International Journal of Geographical Information Science, 26(12), 2267-2276.

doi:10.1080/13658816.2012.722637

Perinbanayagam, R. (2006). Games and Sport in Everyday Life, Dialogues and Narratives of the Self. 